\title{
The experience of nursing women with breastfeeding support: a qualitative inquiry
}

\author{
Kathleen H. Chaput PhD, Carol E. Adair PhD, Alberto Nettel-Aguirre PhD, Richard Musto MD, \\ Suzanne C. Tough PhD
}

\section{Abstract}

Background: Breastfeeding difficulties are a common occurrence, are highly personal and can vary from one infant to the next for any mother. Multiple sources of support, help and advice for breastfeeding are available to nursing mothers. Evidence suggests that the experience of the quality of breastfeeding supports may play an important role in maternal mental health and well-being in the postpartum period. We sought to explore the experiences of nursing mothers with support they received for breastfeeding in order to better inform and optimize existing breastfeeding supports and interventions.

Methods: We conducted a qualitative inquiry of nursing mothers' experiences with help, advice and support for breastfeeding. Participants were asked to provide open-ended, written accounts of their experiences with all sources of breastfeeding support received in the 6 months following the delivery of a healthy full-term infant in Calgary. We conducted qualitative thematic analysis, using constant comparison techniques.

Results: The sample included 86 mothers. Our analyses uncovered 4 emergent themes that contributed to the perceived quality of breastfeeding support: knowledge, effectiveness, sensitivity/emotional support and accessible when sought.

Interpretation: Our study provides a greater understanding of how mothers perceive the quality of the breastfeeding support that they receive, as well as what qualities of breastfeeding support are seen as beneficial or negative. The qualities contributing to the perception of breastfeeding support are important to inform and optimize perinatal care, and potentially reduce the risk of negative mental health outcomes for mothers.

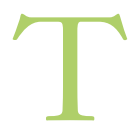
he health benefits of breastfeeding for infants and mothers are globally recognized. ${ }^{1}$ Because of its associations with decreased incidence and severity of infant infections and childhood obesity, and with optimal cognitive and emotional development, international and regional health organizations actively promote the initiation and increased duration of breastfeeding. ${ }^{2-6}$ Qualitative studies suggest that breastfeeding difficulties are a common experience for nursing mothers in the postpartum period, are highly personal and can vary from one infant to the next for the same mother. ${ }^{7-10}$ Many mothers persist through difficulties and breastfeed for longer than 6 months, although the experiences of those who persist with breastfeeding are largely unexplored. ${ }^{10}$ Difficulty with feeding an infant is stressful, and numerous formal and informal breastfeeding supports have emerged to assist nursing mothers. ${ }^{11-13}$ In addition to the difficulties with the act of breastfeeding, qualitative studies suggest that the satisfaction with and perception of breastfeeding support interactions are key factors for maternal well-being. ${ }^{14-17}$
Recent research highlights a rising concern that some approaches to breastfeeding promotion and support may increase emotional burden, stress and anxiety in mothers during a period when stress and mood are linked to later maternal depression. ${ }^{18,19}$ Professional lactation services work toward an ultimate goal of increasing breastfeeding rates, primarily for the benefit of the infant. ${ }^{20}$ Although presumably mindful of maternal well-being, those providing breastfeeding support may underestimate the importance of maternal emotional difficulties in the development of postpartum depression..$^{18,19}$ Reviews show that public health campaigns to promote breastfeeding tend to evade responsibility for the emotional

Competing interests: None declared.

This article has been peer reviewed.

Correspondence to: Kathleen Chaput, khchaput@ucalgary.ca

CMAJ Open 2015. DOI:10.9778/cmajo.20140113 
and psychological impact of breastfeeding promotions on mothers who have difficulties with breastfeeding. ${ }^{19}$ This stance implies that infant feeding choices are a public rather than a personal concern and interferes with mothers' freedom to make such choices. ${ }^{19}$ What is intended as direct personal support may not be perceived as such by some nursing mothers, and the risk of postpartum depression may be unknowingly increased because of increasing pressure, stress and emotional burden. ${ }^{19}$ Two studies of the lived experience of women who discontinued breastfeeding highlight the pressure and stress due to public and professional perceptions of weaning and recommend improved support for women who cease breastfeeding early. ${ }^{8,10}$ Positive encouragement, praise from family and peer support have been identified as predictors of optimal breastfeeding self-efficacy. ${ }^{16,21}$

A greater understanding of the maternal experience of breastfeeding supports and services can inform appropriate approaches, and potentially reduce stress and anxiety, leading to improved maternal mental health. In this study, we aimed to explore the lived experience of nursing mothers who received breastfeeding support in order to better inform and optimize existing breastfeeding supports and interventions.

\section{Methods}

\section{Study design}

The current study was a qualitative inquiry embedded in a larger, mixed-methods, prospective cohort study of the relation between breastfeeding difficulties, breastfeeding support and risk of postpartum depression (methods described elsewhere). ${ }^{22}$

\section{Setting}

We conducted the study among breastfeeding mothers who delivered in any of the 3 active maternity hospitals in Calgary, focusing on the help, advice and support they received for breastfeeding in the first 6 months after delivery.

\section{Sampling}

All mothers aged 18 years or older, who had delivered healthy, full-term singleton infants, and who indicated an intention to breastfeed before delivery were eligible for the study. Research assistants approached all mothers on the postpartum units within 72 hours of delivery, except those who indicated to their nurses that they did not want to hear about the study.

\section{Data collection}

One of the authors (Kathleen Chaput, then a doctoral student of epidemiology, with previous experience conducting qualitative research and a Master of Arts degree in anthropology) met with the mothers individually at the time of recruitment. During the initial visit, Dr. Chaput discussed her personal history as a mother of 2 with breastfeeding problems, experiences with providing peer breastfeeding support and experiences as a student of epidemiology to inform potential participants of the researcher's potential biases, assumptions and reasons for doing the research. She invited participants to provide written journal entries reporting on their experiences with breastfeeding support. Participants completed their journal entries in their homes and submitted them to the research team as answers to qualitative questions on the paper or online questionnaires at birth, and at 6 weeks and 6 months postpartum (Appendix 1, available at www.cmajopen.ca/content/3/3/E305/ suppl/DC1).

Five volunteers (members of the study team or acquaintances of the researchers), who were mothers and who had breastfed at least 1 infant, pilot tested all qualitative questions to ensure the wording would adequately guide respondents and elicit the desired narrative, without constraining the type of information provided. We refined questions based on pilot feedback, until they were deemed acceptable by the pilot testers. We gave each participant a private breastfeeding log at study onset to keep notes, to journal or to document important events and thoughts, and to reference while responding to the questionnaires (Appendix 2, available at www. cmajopen.ca/content/3/3/E305/suppl/DC1). We provided participants with ample space to respond to a series of openended qualitative questions. We encouraged the inclusion of additional paper if necessary and invited participants to share as little or as much information as they deemed necessary to convey their experiences. ${ }^{23} \mathrm{We}$ asked participants to describe for us their "most helpful" and "least helpful" experiences with breastfeeding support and to provide details about the source of support as well as why they felt the support was most helpful, or least helpful, if applicable. We included an additional open question eliciting any additional information or stories, to fully explore all of the support experiences that participants felt were important to share.

The Conjoint Health Research Ethics Board at the University of Calgary granted ethics approval for this study.

\section{Definitions}

Breastfeeding support was very broadly defined as "any advice, help or support with breastfeeding from any source, whether solicited or unsolicited." We chose a nonrestrictive definition of breastfeeding support to avoid constraining the experiences shared by participants and limiting the data collected through an imposed structure, in keeping with recommendations for qualitative inquiry. ${ }^{24,25}$

\section{Analysis}

We sorted the verbatim qualitative narratives received on all 3 questionnaires into those referencing positive or "most helpful" and negative or "least helpful" support experiences. Each set of data (positive and negative) was then analyzed by 2 coders, using summative and emergent thematic content analysis and constant comparison techniques wherein data were manually coded and recoded systematically and grouped according to content into broader and broader themes, until 3-5 consistent, overarching themes emerged. ${ }^{24} \mathrm{We}$ ensured credibility of thematic analyses by member-checking, in which we presented the final themes to a random selection of 15 participants via telephone to ensure a truthful embodiment 
of their experiences, and through negative case analysis, whereby the negative and positive support experiences were compared to elicit more complete information. ${ }^{23} \mathrm{We}$ ensured dependability through an external audit, wherein a doctorallevel researcher outside the study team reviewed the qualitative data and thematic analysis documents, and suggested only minor changes to the analysis decisions and final themes. ${ }^{23-25}$

\section{Results}

Eighty-six women from the overall cohort provided enough written narrative in response to the qualitative questions about experiences with breastfeeding support to contribute to data for analysis. The sample of participating mothers was diverse and reflective of the population composition (Table 1). A range of different ages (mean 31.5, range 20-42 yr), parities, levels of education, marital statuses, incomes and ethnicities were represented. Babies ranged from 32 to 42 weeks of gestation at birth (mean $39.1 \mathrm{wk})$. Twenty-seven mothers (31\%) indicated they had not planned their pregnancy and $32(37 \%)$ had cesarean deliveries. The primary languages spoken at home by participants included English, French, Cantonese, Mandarin, Spanish, Tagalog, Portuguese and Armenian.

Written narrative was received from online and paper questionnaires, and ranged from extensive, candid stories to short, concise descriptions of experiences with breastfeeding support, help or advice. Sources of support included partners, family, friends, strangers, volunteers and health care professionals. The narratives revealed that the women were generally committed to breastfeeding, that feeding difficulties were very stressful, and that there are very specific qualities that contributed to the perception of the support experience, whether positive or negative. The key themes that emerged from the positive experiences with breastfeeding support mirrored the themes that emerged from the negative experience data (Table 2). The final themes of breastfeeding support experiences were knowledge, effectiveness, sensitivity/emotional support and accessible when sought. In some cases, participants described their "best" support experience in terms of lacking negative qualities, rather than by highlighting specific positive qualities, for example, “... didn't put pressure on me ..." and "... gave nonconflicting advice."

A summary of illustrative quotes for each of the key themes is presented in Table 3 .

Minor themes of problem resolution under the "effectiveness" theme and "pressure" under the sensitivity/emotional support theme also emerged. The resolution of problems was a less dominant concept than the theme of pressure, which prevailed in the negative experience descriptions, as well as being a key component that was "avoided" or "lacking" in positive support interactions. The concepts that emerged from the descriptions of negative experiences were directly parallel to the positive experience accounts, indicating that theoretical saturation was achieved in the study.

Member-checking revealed that all themes were acceptable to study participants and were representative of their experiences, and a re-evaluation of data was not deemed necessary.

\section{Interpretation}

The final themes that contributed to experiences with breastfeeding support were knowledge, effectiveness, sensitivity/ emotional support and accessible when sought. Nursing mothers want advice and support from people with the knowledge base to ensure resolution of problems, but it is critical that support be delivered without pressure and with emotional sensitivity to both mother and baby.

Timely and accessible support was clearly perceived as essential to stress mitigation, because feeding times were identified as emotionally pivotal moments. Conversely, unsolicited advice was a dominant thread connecting the negative experiences, indicating that a degree of maternal control is desired in the support and problem-resolution process, and that unsolicited support may undermine attainment of the maternal role..$^{23,26}$

Previous qualitative studies of breastfeeding support in different social and economic contexts from the current study report inconsistent messaging, poor continuity of care, receiving conflicting information, and lack of referral to existing

\begin{tabular}{|c|c|}
\hline Characteristic & No. $(\%)$ \\
\hline \multicolumn{2}{|l|}{ Parity } \\
\hline 1 & $57(66)$ \\
\hline 2 & $21 \quad(24)$ \\
\hline$\geq 3$ & $8 \quad(9)$ \\
\hline \multicolumn{2}{|l|}{ Maternal education } \\
\hline Did not complete high school & $5 \quad(6)$ \\
\hline High school graduate & $14(16)$ \\
\hline College/university/trade graduate & $50 \quad(58)$ \\
\hline Graduate/professional degree & $17(20)$ \\
\hline \multicolumn{2}{|l|}{ Marital status } \\
\hline Single, no partner & $1 \quad(1)$ \\
\hline Single, with partner & $2 \quad(2)$ \\
\hline Married or common-law & $83(96)$ \\
\hline \multicolumn{2}{|l|}{ Annual household income, $n=84$} \\
\hline$<\$ 20000$ & $4 \quad(5)$ \\
\hline$\$ 20000-\$ 49999$ & $8(10)$ \\
\hline$\$ 50$ 000-\$79 999 & $19(23)$ \\
\hline$\geq \$ 80000$ & $53(63)$ \\
\hline \multicolumn{2}{|l|}{ Ethnic background } \\
\hline White & $73(85)$ \\
\hline First Nations & $1 \quad(1)$ \\
\hline South Asian & $2 \quad(2)$ \\
\hline Chinese & $6 \quad(7)$ \\
\hline Filipina & $3 \quad(3)$ \\
\hline Latin American & $1 \quad(1)$ \\
\hline
\end{tabular}




\section{OPEN}

Research

appropriate resources as themes of negative support, which relate to our themes of accessibility, effectiveness and knowledge. ${ }^{16}$ A metasynthesis of qualitative studies assessing women's experiences with professional breastfeeding support reported best practices for breastfeeding support. ${ }^{7}$ These best practices are as follows: "relationship-based care, including continuity and individualization" (congruent with the current study's themes of accessible when sought and emotional sensitivity); "provide practical help to those women who need it" (congruent with effectiveness and accessible when sought); "provide women with information that is realistic, detailed and positively encouraging" (consistent with the themes emotional support, effectiveness and knowledge); "improved communica- tion and information-giving skills" (consistent with our themes of knowledge and effectiveness); and "further development of peer support programs ... including the evaluation of their effectiveness" (congruent with the theme of effectiveness).

The thematic results are also reflective of the important parameters of the broader category of general social support for breastfeeding mothers, indicating that breastfeeding support and social support are not exclusive of one another. ${ }^{27}$

The findings from this study support broad, consistent cross-disciplinary education and support, in line with the World Health Organization, the US Surgeon General, Healthy People 2020 and the Baby-Friendly Hospital Initiative, and reinforce previous recommendations. ${ }^{16,28}$

\section{Table 2: Positive and negative breastfeeding support themes}

\section{Negative}

Knowledge: mothers felt the person had knowledge, skills and experience with regard to breastfeeding and could accurately identify problems

Effectiveness: suggestions and support were effective in resolving the problems or ameliorating the breastfeeding experience

Emotionally positive: the person showed care for mother and baby, were sensitive to emotional strain and did not add to the "pressure" of breastfeeding

Accessibility: support was available and accessible when needed/ solicited compassion or caring
Lacked knowledge: the person could not identify the problem or could not see successes

Ineffective: suggestions and interventions had no effect on problems or made the breastfeeding experience worse

Emotionally negative: the person was perceived as insensitive, increased feelings of pressure on the mother, and/or did not show

Unavailable/unsolicited: the person was either unavailable for support when most needed or offered unsolicited advice that was unwanted

Table 3: Illustrative quotes

\begin{tabular}{|c|c|c|}
\hline Theme & Positive experience & Negative experience \\
\hline Knowledge & $\begin{array}{l}\text { "... she had so much experience, and knew what [the } \\
\text { baby] was doing right away" } \\
\text { "She could answer my questions." } \\
\text { "... was qualified to help." }\end{array}$ & $\begin{array}{l}\text { "... didn't seem to know what she was doing ..." } \\
\text { "... super young nurse who never breastfed before." }\end{array}$ \\
\hline Effectiveness & $\begin{array}{l}\text { "My doula suggested a different position and it really } \\
\text { helped." } \\
\text { "... knew how to fix the problem." } \\
\text { "... we did it together, and it helped immediately." }\end{array}$ & $\begin{array}{l}\text { "Things suggested did not help." } \\
\text { "... focused on the wrong issue, and never figured out how } \\
\text { to solve the actual problem." } \\
\text { "... just made things more complicated." } \\
\text { "Sent me home with an unrealistic routine." }\end{array}$ \\
\hline $\begin{array}{l}\text { Emotional } \\
\text { support }\end{array}$ & $\begin{array}{l}\text { "She had a sense of humour about it, which eased the } \\
\text { tension." } \\
\text { "... was realistic and supportive." } \\
\text { "She made me feel normal even though it wasn't } \\
\text { working." } \\
\text { "... reassured me that my body could do it." } \\
\text { "She suggested solutions and didn't talk about the } \\
\text { benefits of breastfeeding. We all know that, it doesn't } \\
\text { help anything." }\end{array}$ & $\begin{array}{l}\text { "... very emotionally negative nurse put tons of pressure on } \\
\text { me." } \\
\text { "I felt really judged for supplementing once with a bottle, } \\
\text { but I had to feed him." } \\
\text { "One nurse guilted me for giving a soother, and my } \\
\text { daughter had no problems with [breastfeeding]." } \\
\text { "... didn't care about the baby." }\end{array}$ \\
\hline $\begin{array}{l}\text { Accessible when } \\
\text { sought }\end{array}$ & $\begin{array}{l}\text { "... my midwife was there in the moment. Right when I } \\
\text { was about to lose it." } \\
\text { "... practical and I never felt like I was pestering or } \\
\text { bothering her." } \\
\text { "My mom stayed with us, so she could help with every } \\
\text { feeding until we got the hang of it." }\end{array}$ & $\begin{array}{l}\text { "Things were going fine until the lactation consultant came } \\
\text { and started telling me to change how I was doing } \\
\text { everything. We were fine before, and it just stressed me } \\
\text { out." } \\
\text { "I waited for a whole day to see L.C. in hospital. Baby had } \\
4 \text { bottles while waiting = big problem!" }\end{array}$ \\
\hline
\end{tabular}




\section{Limitations}

Written responses limited the scope and depth of our qualitative narrative compared with verbatim transcripts that we might have obtained from in-depth interviews. However, we had a much larger sample of accounts than would have been feasible with interviews, and we reached theoretical saturation. Themes were found to be reflective of the published evidence to date. We ensured our results were dependable, credible, transferable and confirmable within the feasible limits of the project, in order to maximize study rigor and utility for recommendations. Our study lacked the perspectives of support providers, which should be explored in future research.

\section{Conclusion}

For women who are experiencing breastfeeding difficulties, support should be accessible and providers cautioned against providing unsolicited advice. Health care providers should be made aware of the importance of both positive support and qualities perceived as negative to the mental health of nursing mothers. The narratives of women from this and other qualitative studies of breastfeeding support can be synthesized to assist in informing emotionally sensitive support. Structured education for service providers may act as an ideal vehicle for the mobilization of these and other congruent themes.

\section{References}

1. Postpartum care of the mother and newborn: a practical guide. World Health Organization, Department of Reproductive Health and Research (RHR); 2005.

2. Dewey KG, Heinig MJ, Nommsen-Rivers L. Differences in morbidity between breast-fed and formula-fed infants. 7 Pediatr 1995;126:696-702.

3. Kramer MS, Guo T, Platt RW, et al. Infant growth and health outcomes associated with 3 compared with 6 mo of exclusive breastfeeding. Am 7 Clin Nutr 2003;78:291-5

4. Bhandari N, Bahi R, Mazumdar S, et al.; Infant Feeding Study Group. Effect of community-based promotion of exclusive breastfeeding on diarrhoeal illness and growth: a cluster randomized controlled trial. Lancet 2003;361:1418-23.

5. Bachrach VR, Schwarz E, Bacharach L. Breastfeeding and the risk of hospitalization for respiratory disease in infancy: a meta-analysis. Arch Pediatr Adolesc Med 2003;157:237-43.

6. American Academy of Pediatrics Section on Breastfeeding. Breastfeeding and the use of human milk. Pediatrics 2012;129:e827-41.

7. Nelson AM. A metasynthesis of qualitative breastfeeding studies. 7 Midwifery Womens Health 2006;51:e13-20.

8. Mozingo JN, Davis MW, Droppleman PG, et al. "It wasn't working." Women's experiences with short-term breastfeeding. MCN Am 7 Matern Child Nurs 2000;25:120-6.

9. Schmied V, Barclay L. Connection and pleasure, disruption and distress: women's experience of breastfeeding. F Hum Lact 1999;15:325-34.

10. Hauck YL, Irurita VF. Constructing compatibility: managing breast-feeding and weaning from the mother's perspective. Qual Health Res 2002;12:897-914.

11. Renfrew MJ, McCormick FM, Wade A, et al. Support for healthy breastfeeding mothers with healthy term babies. Cochrane Database Syst Rev 2012;(5): CD001141.
12. Shaw-Flach A. Management of common breastfeeding problems. Community Pract 2002;75:432-5

13. Dennis C-L, Hodnett E, Gallop R, et al. The effect of peer support on breastfeeding duration among primiparous women: a randomized controlled trial. CMA7 2002;166:21-8.

14. Nakano AM. [Breastfeeding experiences in a group of women: the limits of "the body for the child" and "the body for oneself"]. Cad Saúde Pública 2003;19 Suppl 2:S355-63.

15. Wambach KA, Cohen SM. Breastfeeding experiences of urban adolescent mothers. 7 Pediatr Nurs 2009;24:244-54.

16. Cross-Barnet C, Augustyn M, Gross S, et al. Long-term breastfeeding support: failing mothers in need. Matern Child Health 7 2012;16:1926-32.

17. Shakespeare J, Blake F, Garcia J. Breast-feeding difficulties experienced by women taking part in a qualitative interview study of postnatal depression. Midwifery 2004;20:251-60.

18. Wolf JB. Is breast really best? Risk and total motherhood in the National Breastfeeding Awareness Campaign. F Health Polit Policy Law 2007;32:595-636.

19. Knaak S. Breast-feeding, bottle-feeding and Dr. Spock: the shifting context of choice. Can Rev Sociol Anthropol 2005;42:197-216.

20. International Lactation Consultant Association [homepage]. Available: www. ilca.org (accessed 2008 Feb. 2).

21. Kingston D, Dennis CL, Sword W. Exploring breast-feeding self-efficacy. 7 Perinat Neonatal Nurs 2007;21:207-15.

22. Chaput K, Nettel-Aguirre A, Musto R, et al. Breastfeeding difficulties, supports and postpartum depression risk in a Canadian birth cohort. CMAJ Open. In press.

23. Rallis SF, Rossman GB, Gajda R. Trustworthiness in evaluation practice: an emphasis on the relational. Eval Program Plann 2007;30:404-9.

24. Lincoln Y, Guba NJ. Naturalistic inquiry. 1st ed. Beverly Hills: Sage Publications; 1985 .

25. Sale J, Brazil K. A strategy to identify critical appraisal criteria for primary mixed methods research. Qual Quant 2004;38:351-65.

26. Cooke M, Schmied V, Sheehan A. An exploration of the relationship between postnatal distress and maternal role attainment, breast feeding problems and breast feeding cessation in Australia. Midwifery 2007;23:66-76.

27. Hughes RB. The development of an instrument to measure perceived emotional, instrumental, and informational support in breastfeeding mothers. Issues Compr Pediatr Nurs 1984;7:357-62.

28. Tough SC, Newburn-Cook CV, Faber AJ, et al. The relationship between self-reported emotional health, demographics, and perceived satisfaction with prenatal care. Int 7 Health Care Qual Assur Inc Leadersh Health Serv 2004; 17:26-38.

Affiliations: Departments of Community Health Sciences (Chaput, Adair, Nettel-Aguirre, Musto, Tough), Paediatrics (Chaput, NettelAguirre, Tough), Psychiatry (Adair), Cumming School of Medicine, University of Calgary; and Alberta Health Services (Musto), Calgary, Alta.

Contributors: Kathleen Chaput was the primary researcher on the study and completed this work as part of her doctoral dissertation research. Kathleen Chaput led conception and design, conducted data acquisition, analysis and interpretation, and drafted the article. Carol Adair, Alberto Nettel-Aguirre and Suzanne Tough contributed substantially to conception and design; Richard Musto made important contributions to the study conception. Suzanne Tough was the principal investigator for this study. Alberto Nettel-Aguirre, Richard Musto, Carol Adair and Suzanne Tough contributed substantially to analysis and interpretation of data, and revised the article critically for important intellectual content. All authors gave final approval of the version to be published and agreed to act as guarantors of the work.

Supplemental information: For reviewer comments and the original submission of this manuscript, please see www.cmajopen.ca/content/3/3/ E305/suppl/DC1 